\title{
Vulnerable Wild Animal Species, Conservation and Genetic Investigations
}

Massimo Giangaspero ${ }^{1 *}$ and Metab Khalaf Salim Al Ghafri ${ }^{2}$

${ }^{1}$ Faculty of Veterinary Medicine, University of Teramo, Italy

${ }^{2}$ Diwan of the Royal Court, Office for Conservation of the Environment, Al Wasta Wildlife Reserve, Oman

\begin{abstract}
To date, approximately 5,600 species of animals are protected by the Convention on International Trade in Endangered Species of Wild Fauna and Flora (CITES) against over-exploitation through international trade. Among mammals, 300 species are considered threatened with extinction. Conservation efforts rely on a wide spectrum of measures, from rising public awareness to adapted legal framework. In this context, wild animal conservation centers represent a core aspect. Accurate management is required also through qualified veterinary care and research activities, including genetic investigations to support conservation strategies.
\end{abstract}

\section{Keywords: Conservation; Genetic; Wild animals}

Different factors such as high exploitation, illegal trade, and habitat loss, are capable of heavily depleting some wild animal and plant species populations and even bringing some species close to extinction. The endangered status of many prominent species raises the need for efficient protection policy, important in order to safeguard these resources for the future.

Primarily, accurate monitoring of the wild fauna is required to support conservation strategies, resulting in comprehensive inventory of the global conservation status of biological species. The Red List of Threatened Species is issued by the International Union for the Conservation of Nature (IUCN), the world's main authority on the conservation status of species. Species are classified by the IUCN Red List into nine groups, on the base of criteria such as rate of decline, population size, area of geographic distribution, and degree of population and distribution fragmentation [1]. In 2012, nearly 2,000 species were added to the Red List, with 4 species to the extinct list and 2 to the rediscovered list. The IUCN assessed a total of 63,837 species which revealed 19,817 are threatened with extinction. With 3,947 described as "critically endangered" and 5,766 as "endangered", while more than 10,000 species are listed as "vulnerable" (species as likely to become endangered unless the circumstances threatening its survival and reproduction improve). At threat are $41 \%$ of amphibian species, $33 \%$ of reef-building corals, $30 \%$ of conifers, $25 \%$ of mammals, and $13 \%$ of birds.

Furthermore, protection policy includes international cooperation to safeguard certain species from over-exploitation. In the spirit of such cooperation, the Convention on International Trade in Endangered Species of Wild Fauna and Flora (CITES) was drafted as a result of a resolution adopted in 1963 by members of IUCN. As international agreement between governments, aiming to ensure that international trade in specimens of wild animals and plants does not threaten their survival, the Convention entered in force in 1975. Nowadays, CITES accounts a large consensus, with 180 members. The species covered by CITES are listed in three Appendices, according to the degree of protection they need [2]. Appendix I includes species threatened with extinction. Trade in specimens of these species is permitted only in exceptional circumstances. Appendix II includes species not necessarily threatened with extinction, but in which trade must be controlled in order to avoid utilization incompatible with their survival. The Appendix III contains species that are protected in at least one country [2]. The CITES-listed species are roughly 5,600 species of animals and 30,000 species of plants. In some cases only a subspecies or geographically separate population of a species is considered. About 300 species of mammals are currently included in Appendix I, for example the Indian rhinoceros (Rhinoceros unicornis) and the Arabian oryx (Oryx leucoryx).

The Indian rhinoceros (Rhinoceros unicornis), also called the greater one-horned rhinoceros and Indian one-horned rhinoceros, listed as a vulnerable species in the IUCN Red List, and listed in CITES Appendix I since 1975, is primarily found in north-eastern India's Assam and in protected areas in the Terai of Nepal, where populations are confined to the riverine grasslands in the foothills of the Himalayas [3]. The Indian rhinoceros once ranged throughout the entire stretch of the Indo-Gangetic Plain, but excessive hunting reduced the natural habitat drastically. In 1910, all rhino hunting became prohibited in India [4]. In 1984, five rhinos were relocated to Dudhwa National Park, four from the fields outside the Pabitora Wildlife Sanctuary and one from Goalpara [5]. To date, about 3,000 rhinos live in the wild, 2,000 of which are found in India's state of Assam alone [6]. The Kaziranga National Park hosts the majority of the Indian rhino's population, thus, representing an important conservation center for the species (Figure 1).

The Arabian oryx (Oryx leucoryx) or white oryx is a medium-sized antelope with a distinct shoulder bump, long, straight horns, and a tufted tail [7]. It is a bovid, and the smallest member of Oryx genus, native to desert and steppe areas of the Arabian Peninsula. The Arabian oryx was extinct in the wild by the early 1970s, but was saved in zoos and private preserves and reintroduced into the wild starting in 1980. In 1986, the Arabian oryx was classified as endangered on the IUCN Red List, and in 2011 it was the first animal to revert to vulnerable status after previously being listed as extinct in the wild. It is listed in CITES Appendix I. In 2011, populations were estimated at over 1,000 individuals in the wild, and 6,000-7,000 individuals in captivity worldwide. One of the conservation centers dedicated to the oryx is the

*Corresponding author: Massimo Giangaspero, Faculty of Veterinary Medicine, University of Teramo, Piazza Aldo Moro 45, 64100 Teramo, Italy, Tel: 0033450392875; E-mail: giangasp@gmail.com

Received April 04, 2014; Accepted April 07, 2014; Published April 10, 2014

Citation: Giangaspero M, Al Ghafri MKS (2014) Vulnerable Wild Animal Species, Conservation and Genetic Investigations. Trop Med Surg 2: e116. doi:10.4172/2329-9088.1000e116

Copyright: $\odot 2014$ Giangaspero M, et al. This is an open-access article distributed under the terms of the Creative Commons Attribution License, which permits unrestricted use, distribution, and reproduction in any medium, provided the original author and source are credited. 
Citation: Giangaspero M, Al Ghafri MKS (2014) Vulnerable Wild Animal Species, Conservation and Genetic Investigations. Trop Med Surg 2: e116. doi:10.4172/2329-9088.1000e116

Page 2 of 2

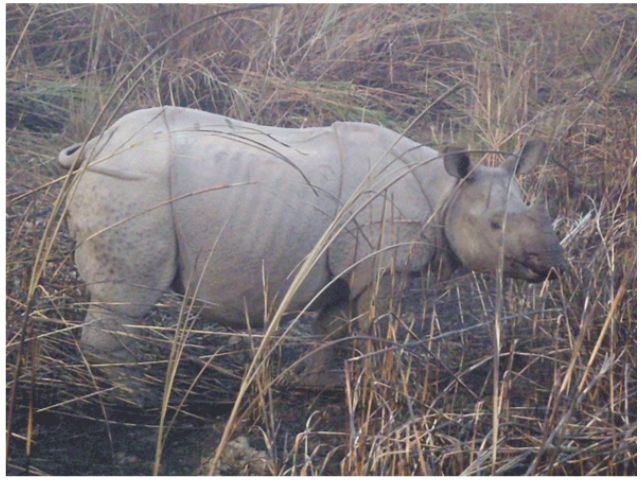

Figure 1: Indian rhinoceros (Rhinoceros unicornis), Kaziranga National park, Assam, India.

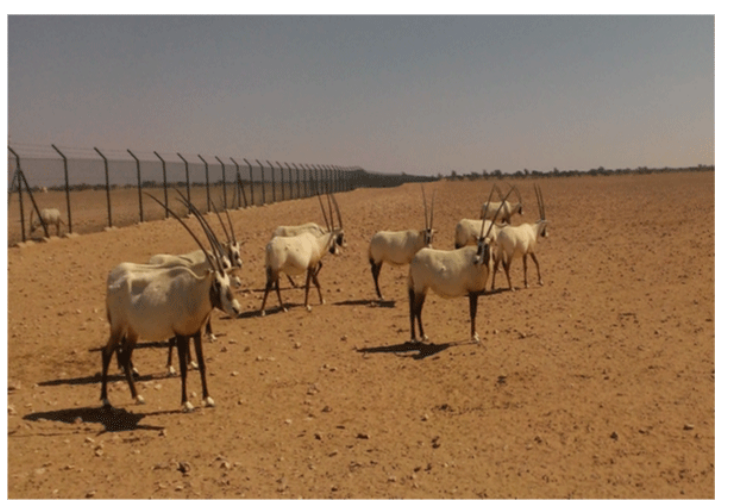

Figure 2: Arabian oryx (Oryx leucoryx), Al Wasta Wildlife Reserve, Oman

Al Wasta Wildlife Reserve, located in Oman. Five hundred fourteen oryx are kept in captivity (Figure 2). In addition, 290 sand gazelle are present in the center. The sand gazelle (Gazella subgutturosa), also known as goitered or black-tailed gazelle, found in different Asian countries, from Turkey, Near East and the Gobi Desert, is also listed in the IUCN red list of vulnerable species.

In the context of conservation efforts, wild animal conservation centers represent a core aspect. The Kaziranga National park and the Al Wasta Wildlife Reserve are example of specific actions dedicated to vulnerable species. Due to their relevant role, conservation centers should operate with high standards, ensuring veterinary care with adequate facilities for clinic, surgery and necropsy. Diagnostic capability should be ensured through laboratory equipment for field observation on hematology, parasitology, bacteriology and virology. Staff should receive appropriate continuous training in the different fields of competence. This will provide relevant information for research purposes and support conservation strategies. Genetic should be integrant part of research activities. The identification of taxonomically appropriate populations of endangered species for captive breeding and reintroduction programs is fundamental. In general, these programs are high-profile and expensive approach to species conservation, and must be based on precise knowledge on taxonomy. For example, until recently, the goitered gazelles were considered to represent a single, albeit polymorphic, species. However, recent genetic studies show one of the subspecies, G. s. marica, is paraphyletic in respect to the other populations of goitered gazelles [8], although gene introgression is observed in the contact zone between the two species [9]. Furthermore, it is necessary to consider the potential for morphologically cryptic species, genetically divergent, which may led to confusion on selected species for repopulation. Accurate taxonomical genetic investigations can be successfully conducted applying molecular testing such as polymerase chain reaction (PCR) and versatile primers that amplify the 5 ' region of the cytochrome $b$ gene of the mitochondrial DNA, for phylogenetic and population research $[10,11]$, or for forensic purposes, for example on animal specimens suspected to be part of illegal trades in wildlife products from the conservation animals [12].

\section{References}

1. International Union for Conservation of Nature (IUCN) (2010) Guidelines for Using the IUCN Red List Categories and Criteria.

2. Convention on International Trade in Endangered Species of Wild Fauna and Flora (2013) Appendices I, II and III.

3. Talukdar BK, Emslie R, Bist SS, Choudhury A, Ellis S, et al. (2008) Rhinoceros unicornis. IUCN Red List of Threatened Species Version 2013.2.

4. Laurie WA, Lang EM, Groves CP (1983) Rhinoceros unicornisMammalian Species. American Society of Mammalogists 211: 1-6.

5. Choudhury AU (1985) Distribution of Indian one-horned rhinoceros. Tiger Paper 12: 25-30.

6. Sarma PK, Talukdar BK, Sarma K (2009) Assessment of habitat change and threats to the greater one-horned rhino (Rhinoceros unicornis) in Pabitora Wildlife Sanctuary, Assam, using multi-temporal satellite data. Pachyderm 46: $18-24$

7. Talbot LM (1960) A Look at Threatened Species. The Fauna Preservation Society 5: 84-91.

8. Wacher T, Wronski T, Hammond RL, Winnney R, Blacket MJ, et al. (2011) Phylogenetic analysis of mitochondrial DNA sequences reveals polyphyly in the goitered gazelle (Gazellasubgutturosa). Conserv Genet 12: 827-831.

9. Murtskhvaladze M, Gurielidze Z, Kopaliani N, Tarkhnishvili D (2012) Gene introgression between Gazellasubguturrosa and G. marica: limitations of maternal inheritance analysis for species identification with conservation purposes. Acta Theriologica 4: 383-386.

10. Kocher TD, Thomas WK, Meyer A, Edwards SV, Paabo S, et al. (1989) Dynamics of mitochondrial DNA evolution in animals: amplification and sequencing with conserved primers. Proc Natl Acad Sci USA 86: 6196-6200.

11. Irwin DM, Kocher TD, Wilson AC (1991) Evolution of the cytochrome b gene of mammals. J Mol Evol 32:128-44.

12. Tsai LC, Huang MT, Hsiao CT, Lin ACY, Chen SJ, et al. (2007) Species identification of animal specimens by cytochrome $b$ gene. Forensic Science Journal 6: 63-65. 